\title{
AN APPLICATION OF DISSIMILAR ANN ALGORITHMS TO IMPROVE THE SIMULATION PERFORMANCE OF FLANK WEAR EXTRAPOLATION IN GFRP COMPOSITE DRILLING

\author{
SATHISH RAO. $\mathbf{U}^{1} \&$ LEWLYN L. RAJ RODRIGUES ${ }^{2}$ \\ ${ }^{I}$ Department of Mechanical and Manufacturing Engineering, Manipal Institute of Technology, Manipal \\ Academy of Higher Education, Manipal, India \\ ${ }^{2}$ Department of Humanities and Management, Manipal Institute of Technology, Manipal \\ Academy of Higher Education, Manipal, India
}

\begin{abstract}
In the recent past, almost all manufacturing and mechanical firms are aiming at reducing the machining cost of the mechanical components due to market competition. One of the ways to reduce the machining cost is to select the optimum machining parameters and their respective levels to get the best productivity. Therefore the research on finding the optimum selection of the machining parameters is gaining importance nowadays. In addition to this, it was observed that, by applying Artificial Intelligence (AI) techniques, the optimized machining parameters could be further fine-tuned and simulated to predict the output parameters accurately. Thus the present research paper applies the AI technique and compares different ANN algorithms to improve the prediction accuracy of the drill flank wear while machining GFRP composites. The flank wear data were generated by performing the drilling process on the GFRP composite in a CNC vertical machining centre by entering different drill machining factors and levels. Later, the neurons of the ANN are trained with drill input and output, experimental data for getting better output prediction accuracy. Following this, the simulation of the drill process parameters was done with different ANN algorithms to select the best algorithm by tuning the ANN architecture. In the next stage, the best selected ANN algorithm along with its tuned architecture is evaluated for different data randomization methods for fine - tuning the optimization. Thus obtained optimized ANN structural configuration is found to be capable of predicting the drill flank wear much efficiently and effectively under the specified work material, tool material and machining combinations and conditions.
\end{abstract}

KEYWORDS: Artificial Neural Network, GFRP Composites, Cutting Speed, Drill Diameter, Cutting Feed Rate \& Drill Flank Wear

Received: Jul 23, 2018; Accepted: Aug 13, 2018; Published: Sep 10, 2018; Paper Id.: IJMPERDOCT201837

\section{INTRODUCTION}

Composite materials take the benefit of the strength to weight ratio and weight to stiffness ratio and the properties of composite materials are superior to those of their individual material constituents. Basically, there are three different types of composites: Polymer Matrix Composites (PMC), Metal Matrix Composites (MMC) and Ceramic Matrix Composite (CMC). In recent times, the application of PMC's in aerospace, marine, automotive and civil industrial sectors is increasing day by day because of its advantages associated with mechanical, structural and aesthetic behaviour. 
In the present scenario, almost all the mechanical and manufacturing industries are aiming at higher productivity and quality to compete and face the challenges in the industrial sectors. As one of the solutions to encounter these challenges, the mechanical and manufacturing industries are in the process of modifying the design or inventing new types of cutting tools that yield greater metal removal rate, longer tool life and better tool stability during machining. But mass production machining with the increased level of machining parameters (i. e., high cutting speed and feed) results in a large amount of thermal intensity at the tool- chip interface zone, which results in the reduction of tool life because of tool wear. This concludes that to improve the cutting tool life, to obtain a better surface finish and to reduce the machining cost, the tool wear is one among those output parameters that needs to be controlled.

In the past few years, analytical methods were applied and mathematical models were developed and used to predict the machining behavior of polymer based composite materials. Most widely used analytical methods were Orthogonal Array (OA) technique of designing the experiments developed by a famous researcher Taguchi for the experimental conduction and the application of Artificial Intelligence (AI) tool for the simulation and analysis part [1,2]. The combination of these two tools became wide spread because of the easiest and fastest method of producing the accurate output. Among different types of AI techniques, application of Artificial Neural Network (ANN) technique became popular due to its capability to handle multivariable non-linear modelling. Due to this, the application of the ANN model to predict the behaviour of cutting tools became popular in the recent days. An Artificial Neural Network (ANN) functions in a similar fashion in which the nervous systems of the brain, functions [3]. The ANN structural configuration combines a large number of interconnected neurons (or processing elements) to provide solutions to specific problems. Zhang and Fedrich [4] in their research work applied ANN in predicting fatigue life, wear and dynamic loading behaviour of Polymer Matrix Composite (PMC) and concluded that ANN tool could be efficiently used for predicting the mechanical behaviour of PMC's because of its similarity with the biological neurons. Hany El kadi and Yousuf Al Assaf [5] used numerous ANN models to forecast the fatigue life of UDGFRE composite. They concluded that the fatigue life can be better predicted through modular network than either a feed forward network or radial basis network. Hany El Kadi [6] in his research work reviewed a number of research work carried out on mechanical modelling of fiber composites using ANN. The work concluded that by fine tuning the ANN architecture, number of hidden layers and the number of neurons in each layer, the accuracy of the result could be improved. The fatigue life of different fiber materials like glass, carbon, kevlar reinforcements with polyester/epoxy matrix materials was studied by Al-Assadi et al. [7]. The result showed that there is no unique ANN architecture or the training method which can produce the best result for all the materials even though there is no change in all the other parameters used for manufacturing the composite. Junhui Jia, Julio F. Davalos [8] considered bonded FRP-wood composite as the study material and used ANN for forecasting the fatigue and observed that the developed ANN model had predicted the fatigue life data accurately in comparison with experimental data. Zhenyu Jiang et al. [9] used ANN technique to polyamide composites to forecast the mechanical and wear behaviour of short fiber reinforced composite. The study concluded that, the increase in the number of neurons leads to better prediction quality, but later it decreased with the increase in the neuron number beyond the limit value. Wei Sha [10] investigated the machin ability of non-reinforced and reinforced PEEK composite using ANN. Kranik [11] studied the effect of specific cutting pressure and the power on PEEK composite (unreinforced and carbon reinforced) using the multilayer feed forward network. The outcome of the research inferred a nonlinear relationship between response parameter and input parameter (cutting conditions). Zhang et al. [12] has used back propagation multilayer perceptron neural network algorithm for the prediction of the coefficient of friction and specific wear rate of polymer composite. They determined that the ANN can be 
used as a powerful tool in material design, process parameter optimization study and characterization analysis of polymer matrix composites.

\section{MATERIALS AND METHODS}

\section{GFRP Material Fabrication}

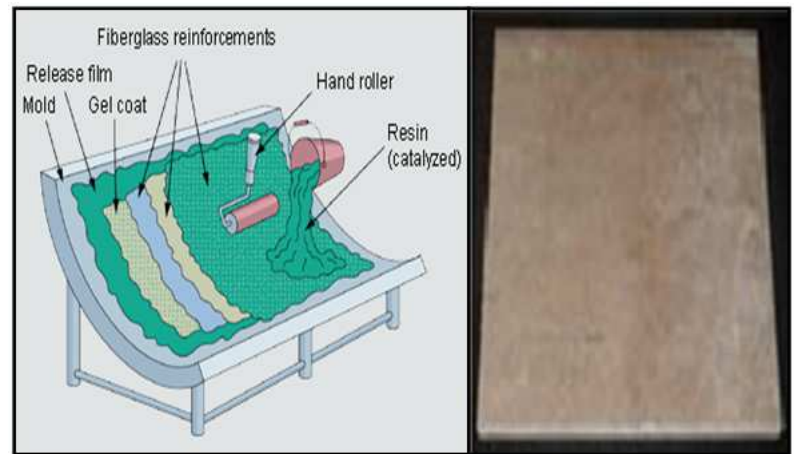

Figure 1: Schematic of Hand Lay-Up Technique and Fabricated GFRP (Source: www.wacker.com)

The wear data are collected from the experimental work by considering drilling process parameters and their different levels [19]. In order to maintain accuracy and data reliability, the dry drilling operation on the GFRP composite was carried out using CNC Vertical Machining Center (VMC).

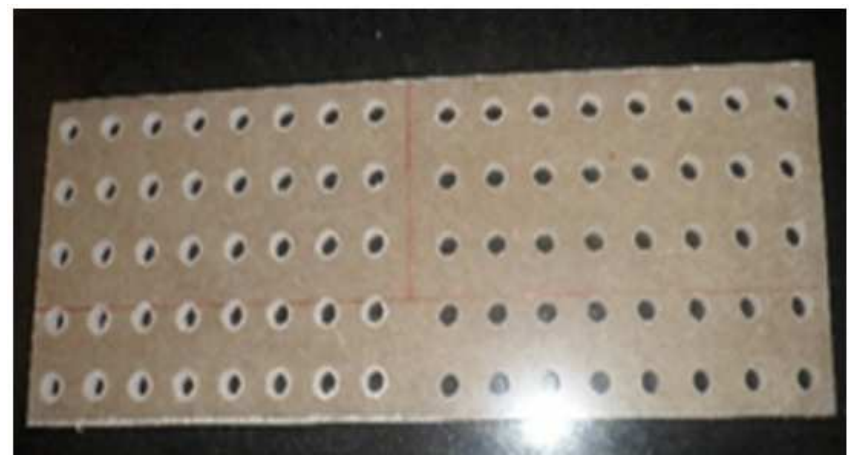

Figure 2: Holes Drilled on the Work Piece for Each Experimental Run

The machining was carried out by drilling 80 holes (Figure 3) on the GFRP composite laminate. 3 machining factors with 3 levels of each was used for experimentation (Table1). Design of Experiments (DoE) with Taguchi's orthogonal array (OA) was applied and 81 experimental runs (L27 orthogonal array with 3 replications for each run) were planned by considering these factors and levels.

The drilled holes were spaced on the GFRP laminate as per the drill hole specification standards for fasteners. Figure 2 shows the 80 holes drilled on the GFRP composite laminate. 


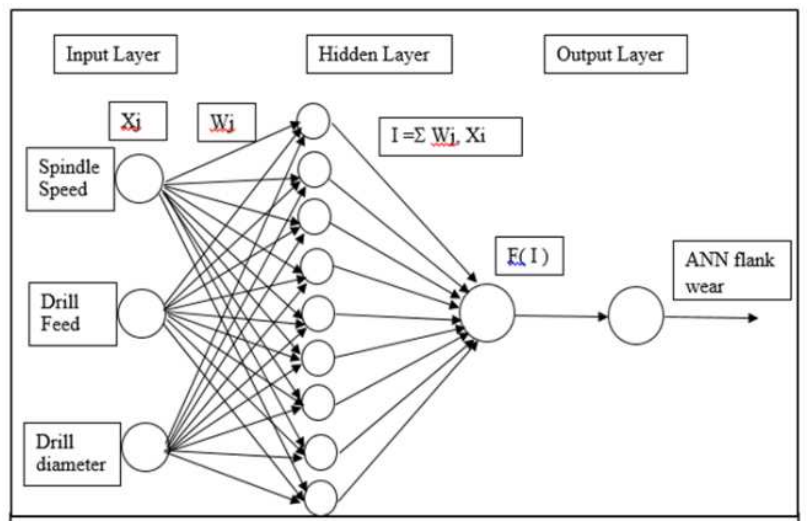

Figure 3: Ann Network Structure of Input and Output Parameters for the Flank Wear Prediction

Each experimental run was executed with a fresh GFRP composite laminate and a fresh drill bit. 80 holes were drilled on the laminate by considering the optimum GFRP material consumption using CATIA software. The drill flank wear was calculated by measuring the difference in the drill land width before and after the machining.

Table 1: Machining Factors and Levels

\begin{tabular}{|c|l|c|c|c|}
\hline \multirow{2}{*}{ Symbol } & \multirow{2}{*}{ Factors } & \multicolumn{3}{|c|}{ No. of Levels } \\
\cline { 3 - 5 } & & Level 1 & Level 2 & Level 3 \\
\hline A & Speed (rpm) & 1200 & 1500 & 1800 \\
\hline B & Feed (mm/rev) & 0.1 & 0.2 & 0.3 \\
\hline C & Drill Diameter $(\mathrm{mm})$ & 6 & 8 & 10 \\
\hline
\end{tabular}

\section{DATASET PREPARATION AND DATA COLLECTION FOR ARTIFICIAL NEURAL NETWORK (ANN)}

The ANN network structure of input and output parameters for training and testing the flank wear prediction is shown in Figure 3.

The flank wear data set containing 81 observations (as shown in the Table 2) was split into training and testing sets. Approximately $75 \%$ of the total observations (i. e., 60 observations) were used for ANN training and $25 \%$ of the total observations (i. e., 21 observations) were used for testing the ANN model. The data sets were designed for fixed data method (i. e., considering first 60 data for training and the next 21 for testing). The optimum training method was selected based on the $\mathrm{R}^{2}$ value, number of neurons in the hidden layer, training and testing accuracy, mean square error and minimum number of epochs required to converge the network.

Table 2: Flank Wear Data for Different Machining Factors and Levels

\begin{tabular}{|c|c|c|c|c|c|c|c|c|c|}
\hline Expt. No. & $\begin{array}{c}\text { Spindle } \\
\text { Speed } \\
(\mathbf{r p m})\end{array}$ & $\begin{array}{c}\text { Drill Feed } \\
(\mathbf{m m} / \mathbf{r e v})\end{array}$ & $\begin{array}{c}\text { Drill } \\
\text { Diameter } \\
(\mathbf{m m})\end{array}$ & $\begin{array}{c}\text { Flank wear } \\
(\text { Experimental }) \\
(\mathbf{m m})\end{array}$ & $\begin{array}{c}\text { Expt. } \\
\mathbf{N o .}\end{array}$ & $\begin{array}{c}\text { Spindle } \\
\text { Speed } \\
(\mathbf{r p m})\end{array}$ & $\begin{array}{c}\text { Drill Feed } \\
(\mathbf{m m} / \mathbf{r e v})\end{array}$ & $\begin{array}{c}\text { Drill } \\
\text { Diameter } \\
(\mathbf{m m})\end{array}$ & $\begin{array}{c}\text { Flank Wear } \\
(\text { Experimental }) \\
(\mathbf{m m})\end{array}$ \\
\hline 1 & 1800 & 0.1 & 6 & 0.312 & 41 & 1500 & 0.1 & 10 & 0.302 \\
\hline 2 & 1800 & 0.1 & 8 & 0.319 & 42 & 1200 & 0.3 & 6 & 0.216 \\
\hline 3 & 1500 & 0.2 & 10 & 0.296 & 43 & 1800 & 0.2 & 10 & 0.334 \\
\hline 4 & 1200 & 0.2 & 8 & 0.238 & 44 & 1200 & 0.1 & 10 & 0.263 \\
\hline 5 & 1200 & 0.1 & 8 & 0.284 & 45 & 1200 & 0.1 & 6 & 0.287 \\
\hline 6 & 1500 & 0.3 & 6 & 0.225 & 46 & 1500 & 0.1 & 6 & 0.296 \\
\hline
\end{tabular}




\begin{tabular}{|c|c|c|c|c|c|c|c|c|c|}
\hline \multicolumn{10}{|c|}{ Table 2: Contd., } \\
\hline 7 & 1500 & 0.3 & 10 & 0.292 & 47 & 1800 & 0.3 & 8 & 0.29 \\
\hline 8 & 1800 & 0.2 & 8 & 0.31 & 48 & 1500 & 0.2 & 6 & 0.252 \\
\hline 9 & 1200 & 0.2 & 10 & 0.298 & 49 & 1200 & 0.3 & 8 & 0.219 \\
\hline 10 & 1200 & 0.2 & 6 & 0.256 & 50 & 1200 & 0.3 & 10 & 0.234 \\
\hline 11 & 1500 & 0.1 & 8 & 0.311 & 51 & 1800 & 0.3 & 6 & 0.238 \\
\hline 12 & 1800 & 0.1 & 10 & 0.365 & 52 & 1800 & 0.2 & 6 & 0.302 \\
\hline 13 & 1500 & 0.2 & 8 & 0.284 & 53 & 1500 & 0.3 & 8 & 0.259 \\
\hline 14 & 1500 & 0.1 & 10 & 0.314 & 54 & 1800 & 0.3 & 10 & 0.318 \\
\hline 15 & 1200 & 0.3 & 6 & 0.218 & 55 & 1800 & 0.1 & 6 & 0.325 \\
\hline 16 & 1800 & 0.2 & 10 & 0.323 & 56 & 1800 & 0.1 & 8 & 0.31 \\
\hline 17 & 1200 & 0.1 & 10 & 0.272 & 57 & 1500 & 0.2 & 10 & 0.301 \\
\hline 18 & 1200 & 0.1 & 6 & 0.316 & 58 & 1200 & 0.2 & 8 & 0.268 \\
\hline 19 & 1500 & 0.1 & 6 & 0.273 & 59 & 1200 & 0.1 & 8 & 0.246 \\
\hline 20 & 1800 & 0.3 & 8 & 0.304 & 60 & 1500 & 0.3 & 6 & 0.212 \\
\hline 21 & 1500 & 0.2 & 6 & 0.254 & 61 & 1500 & 0.3 & 10 & 0.274 \\
\hline 22 & 1200 & 0.3 & 8 & 0.222 & 62 & 1800 & 0.2 & 8 & 0.286 \\
\hline 23 & 1200 & 0.3 & 10 & 0.271 & 63 & 1200 & 0.2 & 10 & 0.261 \\
\hline 24 & 1800 & 0.3 & 6 & 0.233 & 64 & 1200 & 0.2 & 6 & 0.246 \\
\hline 25 & 1800 & 0.2 & 6 & 0.281 & 65 & 1500 & 0.1 & 8 & 0.29 \\
\hline 26 & 1500 & 0.3 & 8 & 0.248 & 66 & 1800 & 0.1 & 10 & 0.336 \\
\hline 27 & 1800 & 0.3 & 10 & 0.306 & 67 & 1500 & 0.2 & 8 & 0.268 \\
\hline 28 & 1800 & 0.1 & 6 & 0.323 & 68 & 1500 & 0.1 & 10 & 0.287 \\
\hline 29 & 1800 & 0.1 & 8 & 0.318 & 69 & 1200 & 0.3 & 6 & 0.214 \\
\hline 30 & 1500 & 0.2 & 10 & 0.287 & 70 & 1800 & 0.2 & 10 & 0.336 \\
\hline 31 & 1200 & 0.2 & 8 & 0.241 & 71 & 1200 & 0.1 & 10 & 0.269 \\
\hline 32 & 1200 & 0.1 & 8 & 0.274 & 72 & 1200 & 0.1 & 6 & 0.301 \\
\hline 33 & 1500 & 0.3 & 6 & 0.226 & 73 & 1500 & 0.1 & 6 & 0.304 \\
\hline 34 & 1500 & 0.3 & 10 & 0.286 & 74 & 1800 & 0.3 & 8 & 0.26 \\
\hline 35 & 1800 & 0.2 & 8 & 0.336 & 75 & 1500 & 0.2 & 6 & 0.256 \\
\hline 36 & 1200 & 0.2 & 10 & 0.275 & 76 & 1200 & 0.3 & 8 & 0.213 \\
\hline 37 & 1200 & 0.2 & 6 & 0.233 & 77 & 1200 & 0.3 & 10 & 0.263 \\
\hline 38 & 1500 & 0.1 & 8 & 0.29 & 78 & 1800 & 0.3 & 6 & 0.225 \\
\hline 39 & 1800 & 0.1 & 10 & 0.34 & 79 & 1800 & 0.2 & 6 & 0.291 \\
\hline \multirow[t]{2}{*}{40} & 1500 & 0.2 & 8 & 0.261 & 80 & 1500 & 0.3 & 8 & 0.251 \\
\hline & & & & & 81 & 1800 & 0.3 & 10 & 0.322 \\
\hline
\end{tabular}

For almost all the ANN simulation models some amount of pre-processing is always carried out on the input and output the raw data in order to normalize and make it suitable for the network. The dataset used in the present study was normalized using column normalization in MATLAB software.

\section{Drill Flank Wear Simulation using different ANN Algorithms}

Seven different ANN back propagation algorithms were used for the simulation and each algorithm took the data collected from experimental flank wear to simulate the flank wear model. The algorithms selected for flank wear simulation are 
- $\quad$ Scaled conjugate gradient back propagation (SCG)

- $\quad$ BFGS quasi-Newton back propagation (BFG)

- Conjugate gradient back propagation with Polak-Ribiére updates (CGP)

- Gradient descent with adaptive learning rate back propagation (GDA)

- $\quad$ Resilient back propagation (RP)

- $\quad$ Gradient descent back propagation (GD)

- $\quad$ Lavenberg - Marquedt algorithm

Neural Network Toolbox of MATLAB software was used for all the above training algorithms. The learning function could be applied to individual weights and biases within the network. All these network training functions update weight and bias values according to the respective algorithm methods. Learning functions were used to adapt networks and the present research had used Gradient Descent with Momentum weight and bias LEARNing function (LEARNGDM) for learning and TANgent SIGmoid (TANSIG) as the transfer function for the network designed.

In the training stage, in order to obtain the output (drill flank tool wear) precisely and to design the best network architecture, each algorithm was tested with the sigmoid transfer function and the number of neurons in the hidden layer varied from 2-9.

Table 3: Results of the Simulation of Flank Wear using Different Ann Algorithm

\begin{tabular}{|c|c|c|c|c|c|c|c|c|}
\hline Algorithm & $\mathrm{Nu}$ & Epochs & MSE & Cl_Ac_Trg & Cl_Ac_Tst & MRE_Trg & MRE_Tst & $\mathbf{R}^{2}$ \\
\hline \multirow{8}{*}{$\mathrm{RP}$} & 2 & 1000 & 0.0125 & 61.67 & 52.38 & 4.926 & 5.94 & 0.99596 \\
\hline & 3 & 1000 & 0.0078 & 71.67 & 80.95 & 3.77 & 4.06 & 0.99762 \\
\hline & 4 & 1000 & 0.0085 & 66.67 & 61.90 & 4.12 & 4.69 & 0.99727 \\
\hline & 5 & 1000 & 0.0126 & 60.00 & 52.38 & 5.00 & 5.92 & 0.99594 \\
\hline & 6 & 1000 & 0.0125 & 60.00 & 52.38 & 4.97 & 6.01 & 0.99597 \\
\hline & 7 & 1000 & 0.0125 & 60.00 & 52.38 & 4.996 & 5.98 & 0.99597 \\
\hline & 8 & 1000 & 0.0062 & 76.67 & 76.19 & 3.43 & 3.77 & 0.99799 \\
\hline & 9 & 1000 & 0.0125 & 60.00 & 52.38 & 4.999 & 5.95 & 0.99596 \\
\hline \multirow{8}{*}{ GD } & 2 & 1000 & 0.0135 & 56.67 & 47.62 & 5.349 & 6.07 & 0.99515 \\
\hline & 3 & 1000 & 0.0134 & 51.67 & 52.38 & 5.396 & 6.08 & 0.99575 \\
\hline & 4 & 1000 & 0.0125 & 56.67 & 52.38 & 4.959 & 5.84 & 0.99597 \\
\hline & 5 & 1000 & 0.0126 & 58.33 & 52.38 & 4.968 & 5.942 & 0.99594 \\
\hline & 6 & 1000 & 0.0125 & 60.00 & 52.38 & 4.984 & 5.94 & 0.99597 \\
\hline & 7 & 1000 & 0.0125 & 60.00 & 52.38 & 5.008 & 5.91 & 0.99594 \\
\hline & 8 & 1000 & 0.0125 & 60.00 & 52.38 & 5.002 & 5.96 & 0.99596 \\
\hline & 9 & 1000 & 0.0125 & 61.67 & 52.38 & 5.006 & 5.93 & 0.99596 \\
\hline \multirow{8}{*}{ SCG } & 2 & 343 & 0.008 & 70.00 & 57.14 & 3.78 & 4.51 & 0.99749 \\
\hline & 3 & 1000 & 0.0058 & 78.33 & 80.95 & 3.26 & 3.76 & 0.99810 \\
\hline & 4 & 1000 & 0.0044 & 83.33 & 71.43 & 3.03 & 4.17 & 0.99827 \\
\hline & 5 & 1000 & 0.0041 & 86.67 & 66.67 & 2.98 & 4.28 & 0.99829 \\
\hline & 6 & 1000 & 0.0039 & 90.00 & 71.43 & 2.88 & 4.21 & 0.99833 \\
\hline & 7 & 1000 & 0.0038 & 90.00 & 71.43 & 2.87 & 4.234 & 0.99832 \\
\hline & 8 & 1000 & 0.0039 & 90.00 & 71.43 & 2.86 & 4.20 & 0.99832 \\
\hline & 9 & 765 & 0.0038 & 90.00 & 71.43 & 2.872 & 4.235 & 0.99832 \\
\hline \multirow{3}{*}{ BFG } & 2 & 116 & 0.0080 & 70.00 & 57.14 & 3.78 & 4.50 & 0.99748 \\
\hline & 3 & 1000 & 0.0068 & 71.67 & 76.19 & 3.55 & 3.36 & 0.99814 \\
\hline & 4 & 1000 & 0.0056 & 76.67 & 80.95 & 3.10 & 3.93 & 0.99812 \\
\hline
\end{tabular}




\begin{tabular}{|c|c|c|c|c|c|c|c|c|}
\hline \multirow[t]{5}{*}{ 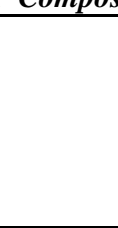 } & 5 & 1000 & 0.0048 & 81.67 & 71.43 & 3.17 & 3.57 & 0.99826 \\
\hline & 6 & 1000 & 0.0040 & 83.33 & 76.19 & 2.86 & 6.16 & 0.99832 \\
\hline & 7 & 1000 & 0.0052 & 90.00 & 76.19 & 2.87 & 4.18 & 0.99835 \\
\hline & 8 & 1000 & 0.0049 & 88.33 & 76.19 & 2.871 & 4.21 & 0.99831 \\
\hline & 9 & 1000 & 0.0052 & 90.00 & 71.43 & 2.874 & 4.23 & 0.99832 \\
\hline \multirow{8}{*}{ CGP } & 2 & 165 & 0.0080 & 70.00 & 57.14 & 3.78 & 4.50 & 0.99748 \\
\hline & 3 & 337 & 0.0061 & 73.33 & 76.17 & 3.42 & 3.672 & 0.99804 \\
\hline & 4 & 1000 & 0.0053 & 78.33 & 71.43 & 3.17 & 3.673 & 0.99828 \\
\hline & 5 & 1000 & 0.0047 & 86.67 & 71.43 & 2.98 & 3.95 & 0.99824 \\
\hline & 6 & 1000 & 0.0039 & 88.33 & 71.43 & 2.91 & 4.13 & 0.99834 \\
\hline & 7 & 612 & 0.0038 & 90.00 & 71.43 & 2.872 & 4.234 & 0.99833 \\
\hline & 8 & 738 & 0.0038 & 90.00 & 71.43 & 2.875 & 4.235 & 0.99833 \\
\hline & 9 & 414 & 0.0038 & 90.00 & 71.43 & 2.873 & 4.237 & 0.99832 \\
\hline \multirow{8}{*}{ GDM } & 2 & 759 & 0.0079 & 73.33 & 71.43 & 3.71 & 4.06 & 0.99755 \\
\hline & 3 & 976 & 0.0065 & 73.33 & 76.19 & 3.51 & 3.813 & 0.99797 \\
\hline & 4 & 985 & 0.0071 & 71.67 & 76.19 & 3.61 & 3.815 & 0.99784 \\
\hline & 5 & 987 & 0.0067 & 70.00 & 76.19 & 3.602 & 3.998 & 0.99792 \\
\hline & 6 & 983 & 0.0075 & 73.33 & 71.43 & 3.604 & 3.980 & 0.99766 \\
\hline & 7 & 999 & 0.0066 & 75.00 & 76.19 & 3.61 & 3.86 & 0.99793 \\
\hline & 8 & 954 & 0.0077 & 73.33 & 71.43 & 3.70 & 4.08 & 0.99761 \\
\hline & 9 & 996 & 0.0075 & 73.33 & 71.43 & 3.603 & 3.984 & 0.99765 \\
\hline \multirow{8}{*}{ LM } & 2 & 1000 & 0.0077 & 76.67 & 57.14 & 3.72 & 4.66 & 0.99749 \\
\hline & 3 & 218 & 0.0057 & 80.00 & 80.95 & 3.25 & 3.79 & 0.99811 \\
\hline & 4 & 225 & 0.0042 & 86.67 & 71.43 & 2.93 & 4.05 & 0.99827 \\
\hline & 5 & 37 & 0.0038 & 91.67 & 71.43 & 2.870 & 4.22 & 0.99834 \\
\hline & 6 & 60 & 0.0039 & 90.00 & 71.43 & 2.874 & 4.24 & 0.99832 \\
\hline & 7 & 1000 & 0.0039 & 90.00 & 71.43 & 2.873 & 4.20 & 0.99833 \\
\hline & 8 & 60 & 0.0038 & 90.00 & 71.43 & 2.874 & 4.23 & 0.99832 \\
\hline & 9 & 1000 & 0.0038 & 90.00 & 71.43 & 2.874 & 4.24 & 0.99832 \\
\hline
\end{tabular}

Thus, all the seven neural network structures were examined by changing the number of neurons in the hidden layer from 2 to 9. Thus the neural networks with architecture 3-2-1, 3-3-1, 3-4-1, 3-5-1, 3-6-1, 3-7-1, 3-8-1 and 3-9-1 were considered for simulation and optimization of the drill flank wear.

The artificial neural network, thus developed was trained by setting the training epochs (cycles) to 1,000 for each network architecture. The objective of the training was to minimize the Mean Square Error (MSE). For this, a computer program was developed in MATLAB software to predict the flank tool wear in the machining of GFRP composites using a HSS drill.

Gradient Descent Method (GDM) was used to minimize the mean squared error between the network output and the actual error rate. The training error continued to decrease as the number of epoch's increased. Repeated runs were performed to get the neural network converged. Weights were initialized to random values and networks are run until at least one of the following termination conditions was satisfied:

- Maximum Epoch

- Minimum Gradient

- Performance Goal

The different statistical parameters for the comparison of ANN model for all the training algorithms are given in the Table 3. The efficiency of the network was measured by taking one of the following parameters into account: 
- $\mathrm{R}^{2}$ value

- 2. Number of epochs taken to converge the network.

- $\quad$ 3. The Mean Square Error (MSE) calculated.

From Table 3 it was evident that the statistical parametric results of Levenberg Marquardt algorithm (LM algorithm) were the best ones compared to other algorithms. TrainLM was a network training function that updated weight and bias values according to Levenberg-Marquardt optimization. TrainLM was found as the fastest back propagation algorithm in the toolbox. Because of these reasons, LM-ANN algorithm is considered as the best ANN algorithm for the simulation of HSS drill flank wear while machining GFRP composites.

The training stops when any of these condition occurs:

- The maximum number of epochs is reached.

- The maximum amount of time is exceeded.

- Performance is minimized to the goal.

Table 4 shows the detailed summary of the LM-ANN algorithm.

Table 4: Summary of the LM ANN algorithm

\begin{tabular}{|l|l|}
\hline Object modelled & Drill Flank wear \\
\hline Input Neuron & Spindle speed, Drill feed and Drill diameter \\
\hline \multicolumn{1}{|c|}{ Network Structure } \\
\hline Network Type & Feed forward back Propagation \\
\hline Transfer Function & Tansig \\
\hline Training Function & Network training function that updates weight and bias values \\
\hline Learning Function & Gradient descent with momentum back propagation Method \\
\hline & \multicolumn{1}{|c|}{ Learning Conditions } \\
\hline Learning Scheme & Supervised learning \\
\hline Learning Rule & Gradient descent rule \\
\hline Input Neuron & Four \\
\hline Output Neuron & One \\
\hline Sample pattern vector & 60 (For training), 21(for testing) \\
\hline Number of hidden layer & 01 \\
\hline Neurons in hidden layer & $02-09$ \\
\hline Learning rate & 0.1 \\
\hline Minimum performance Gradient & $1 \mathrm{e}-10$ \\
\hline Maximum mu & $1 \mathrm{e} 10$ \\
\hline Performance goal/Error goal & $1 \mathrm{e}-10$ \\
\hline Maximum epochs(cycles) set & 1000 \\
\hline $\mathrm{R}^{2}$ at the end of the training & 0.99843 \\
\hline MRE at the end of the training & 0.0038 \\
\hline Number of Epochs & 37 \\
\hline
\end{tabular}

In the previous simulation, the first 60 data from the flank wear data set were fixed and as training data and the next 21 data were fixed and used as testing data. To overcome this an attempt was made in the present research to shuffle or randomize the data to check for improvement in the ANN training efficiency. So, the flank wear database was randomized in two different ways. They were: 
In this method data randomization was done by generating random numbers and arranging these numbers along with the data in a specific order. To do this, all the flank wear data were fed to MS-EXCEL software and the random numbers were generated for each of the flank wear data. These random numbers were arranged in a particular order. When the generated numbers were shuffled to arrange them in a particular order, the data corresponding to the random number were also shuffled accordingly. The best ANN-LM drill flank wear simulation result obtained for the random number generation method is shown in the Table 5.

Table 5: Best ANN configuration for Randomisation method

\begin{tabular}{|c|c|c|c|c|c|c|c|}
\hline $\begin{array}{c}\text { Number of } \\
\text { neurons }\end{array}$ & $\begin{array}{c}\text { Number of } \\
\text { epochs }\end{array}$ & MSE & $\begin{array}{c}\text { Training } \\
\text { Accuracy }\end{array}$ & $\begin{array}{c}\text { Testing } \\
\text { Accuracy }\end{array}$ & MRE_Trg & MRE_Tst & $\mathbf{R}^{\mathbf{2}}$ \\
\hline 2 & 1000 & 0.0053 & 75 & 57.14 & 3.147833 & 4.820020 & 0.997514 \\
\hline 3 & 1000 & 0.0039 & 85 & 61.9 & 2.672898 & 4.147665 & 0.997907 \\
\hline 4 & 555 & 0.0030 & 91.67 & 71.43 & 2.533812 & 3.180325 & 0.998028 \\
\hline 5 & 1000 & 0.0029 & 93.33 & 76.19 & 2.434563 & 2.794786 & 0.997951 \\
\hline 6 & 48 & 0.0027 & 95 & 76.19 & 2.351966 & 2.794786 & 0.998038 \\
\hline 7 & 93 & 0.0027 & 95 & 76.19 & 2.351966 & 2.794786 & 0.998038 \\
\hline 8 & 62 & 0.0027 & 95 & 76.19 & 2.351966 & 2.794786 & 0.998038 \\
\hline 9 & 52 & 0.0027 & 95 & 76.19 & 2.351966 & 2.794786 & 0.998038 \\
\hline
\end{tabular}

\section{N-Fold Method of Cross Validation (Boot Strap Method)}

Cross validation is a statistical method that divides data into $\mathrm{n}$ folds or partitions of approximately the same size. One fold is used for classifying testing and the other (n-1) folds are used for classifier training. The process is repeated so that each of the $\mathrm{n}$ fold is used for testing. The resulting process is known as $\mathrm{n}$ - fold cross validation.

In Tenfold stratified cross validation case, the data are divided randomly into ten subsets (classifier) of approximately the same size. The classifier is run 10 times. In each run, the classifier uses a different subset as the testing set while the other subsets are combined using as a training set. This results in ten different accuracy/error estimate for the learner that can be averaged to provide an overall accuracy/error estimate. In the present research, 81 experimental data were divided into 10 groups, each group comprising of 8 data. Each group was simulated as testing group and the data remaining in the other groups were treated as training data, using ANN - LM algorithm. Out of all the simulated results, the best result was obtained for the ANN-LM configuration was tabulated in the Table 6.

Table 6: Best ANN Configuration for Tenfold Stratified Cross Validation Method

\begin{tabular}{|c|c|c|c|c|c|c|c|}
\hline $\begin{array}{c}\text { Number of } \\
\text { neurons }\end{array}$ & $\begin{array}{c}\text { Number of } \\
\text { epochs }\end{array}$ & MSE & $\begin{array}{c}\text { Training } \\
\text { Accuracy }\end{array}$ & $\begin{array}{c}\text { Testing } \\
\text { Accuracy }\end{array}$ & MRE_Trg & MRE_Tst & $\mathbf{R}^{\mathbf{2}}$ \\
\hline 2 & 481 & 0.0075 & 72.22 & 48.15 & 3.664786 & 4.944631 & 0.997433 \\
\hline 3 & 1000 & 0.0054 & 74.07 & 74.07 & 3.20104 & 4.264492 & 0.997955 \\
\hline 4 & 1000 & 0.0037 & 88.89 & 59.26 & 2.668872 & 4.662967 & 0.9981 \\
\hline 5 & 1000 & 0.0036 & 90.74 & 62.96 & 2.634424 & 4.720325 & 0.998113 \\
\hline 6 & 115 & 0.003 & 94.44 & 66.67 & 2.420535 & 4.724819 & 0.998204 \\
\hline 7 & 57 & 0.003 & 94.44 & 66.67 & 2.420535 & 4.724819 & 0.998204 \\
\hline 8 & 44 & 0.003 & 94.44 & 66.67 & 2.420535 & 4.724819 & 0.998204 \\
\hline 9 & 54 & 0.003 & 94.44 & 66.67 & 2.420535 & 4.724819 & 0.998204 \\
\hline
\end{tabular}




\section{COMPARISON OF BEST ANN CONFIGURATION RESULTS FOR DIFFERENT ANN DATABASES}

Three best configurations of each type of dataset (Fixed, Randomised and Tenfold) were again compared (Table 7) to select the optimum ANN configuration for drill process factor stimulation. The comparison is done based on the following ANN parameters:

- $\quad \mathrm{R}^{2}$ value

- Number of epochs taken to converge the network.

- Number of neurons in the hidden layer.

- $\quad$ The Mean Square Error (MSE) calculated.

- $\quad$ Training and testing accuracy.

Table 7: Comparison of ANN Configuration for Different Randomization Methods

\begin{tabular}{|l|c|c|c|c|c|c|c|c|}
\hline $\begin{array}{c}\text { Methods Applied } \\
\text { to Flank Wear } \\
\text { Database }\end{array}$ & $\begin{array}{c}\text { No. of } \\
\text { Neurons }\end{array}$ & $\begin{array}{c}\text { No. of } \\
\text { Epochs }\end{array}$ & MSE & $\begin{array}{c}\text { Training } \\
\text { Accuracy }\end{array}$ & $\begin{array}{c}\text { Testing } \\
\text { Accuracy }\end{array}$ & MRE_Trg & MRE_Tst & $\mathbf{R}^{2}$ \\
\hline $\begin{array}{l}\text { Fixed number } \\
\text { database method }\end{array}$ & 5 & 37 & 0.0038 & 91.67 & 71.43 & 2.870 & 4.22 & 0.998034 \\
\hline $\begin{array}{l}\text { Randomised } \\
\text { number cross } \\
\text { validation method }\end{array}$ & 6 & 48 & 0.0027 & 95 & 76.19 & 2.352 & 2.795 & 0.998038 \\
\hline $\begin{array}{l}\text { Tenfold method of } \\
\text { data base } \\
\text { randomization }\end{array}$ & 8 & 44 & 0.0030 & 94.44 & 66.67 & 2.421 & 4.725 & 0.998204 \\
\hline
\end{tabular}

By comparing different ANN parameters (refer Table 7), it was found that that the Randomised number cross validation method with 3-6-1 ANN configuration using Levenberg-Marquardt Algorithm provided the optimum ANN simulation network for simulating the drill process factors while machining GFRP composites with HSS twist drills.

\section{RESULTS AND DISCUSSIONS}

In this research work, a computer program was developed in the MATLAB platform to predict the drill flank wear. The input parameters of the network were spindle speed, drill feed and drill diameter whereas its output parameter was drill flank wear. It was apparent from Table 2 that, the prediction performances for both training and testing sets of the tool wear showed a quite satisfactory accuracy (error $<5 \%$ ). The $\mathrm{R}^{2}$ values of the learning algorithms for both training and testing sets were higher than 0.99 (0.9983). The LM learning algorithm reached to optimal solutions with a smaller number of neurons (5) in the hidden layer and with a minimum number of epochs (37) when compared to other learning algorithms. Also from the results of the simulation (Refer Table 2), it was evident that the performance of the LM algorithm in simulating the process parameters for predicting drill flank wear was better even with respect to other parameters. Another remarkable point in Table 3, was that the best results were obtained with 3-5-1 network configuration (with Training Accuracy $=91.67 \%$ ) of Lavenberg Marquedt $(\mathrm{LM})$ algorithm, which indicates the optimal network structure for predicting the drill flank wear.

So, from all the above observations, findings and results it can be concluded that Lavenberg - Marquedt algorithm can perform better compare to other ANN algorithms in simulating the drill process parameters for predicting the drill 
flank wear for the identified work and tool material and machining conditions. From the Table 7, it was also evident that the randomized data method gave better results in terms of Mean Square Error (MSE) value which was comparatively minimum (0.0027). Another remarkable point in the Table 7, was that the best results were obtained with 3-6-1 network structure for Training Accuracy (95\%) and Testing Accuracy (76.19\%).

\section{CONCLUSIONS}

In this work, ANN simulation of Flank tool wear of the drill was carried out for the machining of GFRP composite material for different combinations of cutting parameters. This study also deals with the selection of the best ANN algorithm for the prediction of drill flank wear. An ANN model for predicting the drill tool wear was developed using experimental values. Then, the performance of the ANN model were evaluated by comparing the performance of different back propagation algorithms. After training it was concluded that, out of the seven learning algorithms compared, the best and fastest ANN results were obtained by the Lavenberg Marquedt (LM) learning algorithm with the following findings:

- Best results were obtained with 3-5-1 network structure configuration and with a Training Accuracy of 91.67\% using Levenberg-Marquardt (LM) algorithm.

- It was observed that the $\mathrm{R}^{2}$ value for all the flank wear data simulated using the LM algorithm was found to be 0.998324 which was learned to be very satisfactory.

- The randomized data method for ANN simulation with 3-6-1 configuration gave best results for Mean Square Error (MSE) value which is comparatively minimum (0.0027) and the best Training Accuracy (95\%) as well as Testing Accuracy (76.19\%) values for simulating the drill process factors while machining GFRP composites with HSS drills.

- Therefore, instead of time-consuming experiments, it was highly recommended the usage of ANN in predicting the tool flank wear in the drilling of GFRP composite materials using HSS tools.

\section{REFERENCES}

1. Ranjit Roy, A Primer on Taguchi Method (Society of Manufacturing Engineer, 1990, II Edition).

2. T. F. Cheng, Taguchi Method, Sep 2001, http://www.timeihk.com/TechnicalInfo/CADCAM/Taguchi Method.pdf.

3. I. Aleksander and H. Morton, An introduction to neural computing (Chapman and Hall; 1990).

4. Z. Zhang and K. Friedrich // Composite Science Technology, vol. 63(2003) pp. 2029.

5. Hany El Kadi and Yousuf Al Asaaf //Composite Structures, vol.55(2002), pp. 239.

6. Hany El Kadi, Composite Structures, vol. 73(2006) 1.

7. M. Al-Assadi, H. El Kadi and I. M. Deiab, Applied Composite Materials, vol. 17(2010), pp. 1.

8. Junhui Jia and Julio F. Davalos // Composite Structures, vol. 74(2006) pp. 106.

9. Zhenyu Jiang, Lada Gyurova, Zhong Zhang, Klaus Friedrich and Alois K. Schlar // Materials and Design, vol.29(2008), pp. 628.

10. Wei Sha, Journal of Reinforced Plastics and Composites, DOI: 10.1177/0731684411400110. 
11. S. R. Karnik, V. N. Gaitonde, Francisco Mata and J. Paulo Davim, Journal of Reinforced Plastics and Composites, vol. 27(2008), pp.751.

12. Z. Zhang, K. Friedrich and K. Velten, Wear, vol. 252(2002), pp. 668.

13. E. Kilickap, Expert Systems with Applications, vol. 37(2010), pp. 6116.

14. Amar Patnaik, Alok Satapathy, S. S. Mahapatra and R. R. Dash, Journal of Reinforced Plastics and Composites, vol. 27(2008), pp. 871.

15. C. C. Tsao and H. Hocheng, International Journal of Machine Tools Manufacturing, vol. 44 (2004), pp. 1085.

16. C. C. Tsao and H. Hocheng, Journal of Materials Processing Technology, vol. 203(2008) pp. 342.

17. N. S. Mohana, S. M. Kulkarni and Ramachandra, Journal of Materials Processing Technology vol. 186(2007), pp. 265.

18. Alok Satapathy and Amar Patnaik, Journal of Reinforced Plastics and Composites, vol. 29(2010), pp. 2883.

19. Sathish Rao U., Dr. Lewlyn L. R. Rodrigues, Indian Journal of Science and Technology, volume 8(29): 2015, pp. 1-9.

20. Sathish Rao U. and Lewlyn L R Rodrigues, International Journal of Mechanical Engineering and Technology, volume 8, issue 1, January 2017, pp. 120-131.

21. Moosazadeh, S., \& Shahmohamad, F. N. Drilling Optimization Using Minimum Energy Concept. 